\title{
Effect of Metformin on Endometrial Thickness and Subendometrial Flow Patterns in Anovulatory Patients with Polycystic Ovarian Syndrome
}

\author{
Waleed M. Khalaf ${ }^{1 *}$, Sherif A. Akl ${ }^{1}$, Rania R. Ramadan ${ }^{2}$ \\ ${ }^{1}$ Obstetrics and Gynecology Department, Faculty of Medicine, Ain Shams University, Cairo, Egypt \\ ${ }^{2}$ Misr University for Sciences and Technology, Giza, Egypt \\ Email: *waleed.khalaf1980@yahoo.com
}

How to cite this paper: Khalaf, W.M., Akl, S.A. and Ramadan, R.R. (2018) Effect of Metformin on Endometrial Thickness and Subendometrial Flow Patterns in Anovulatory Patients with Polycystic Ovarian Syndrome. Open Journal of Obstetrics and Gynecology, 8, 1465-1475.

https://doi.org/10.4236/ojog.2018.814148

Received: November 8, 2018

Accepted: December 1, 2018

Published: December 4, 2018

Copyright $\odot 2018$ by authors and Scientific Research Publishing Inc. This work is licensed under the Creative Commons Attribution International License (CC BY 4.0).

http://creativecommons.org/licenses/by/4.0/

\section{Open Access}

\begin{abstract}
Background: Polycystic ovarian syndrome (PCOS) is considered the commonest endocrinological disorder affecting reproductive aged women. PCOS compromises fertility through various pathways. These pathways include hyperandrogenism, insulin resistance and impedance of the uterine and endometrial blood flow. Metformin improves the blood flow to the endometrium. It acts by reducing androgen level and correction of insulin resistance. Endometrial vascular indices were evaluated in this study to evaluate endometrial receptivity in anovulatory patients with PCOS. Aim of the Work: To evaluate the outcome of metformin administration in anovulatory patients with PCOS and its effect on the endometrium. This included its role in ovulation and improvement of pregnancy rates. Patients and Methods: This study included 85 patients from Ain Shams University outpatient infertility clinics from $1^{\text {st }}$ of January, 2018 till $30^{\text {th }}$ of June, 2018. We investigated these patients before treatment with ultrasound on day 14,21 . We evaluated endometrial thickness, uterine artery flow pattern, endometrial and subendometrial flow patterns. The patients received metformin $500 \mathrm{mg}$ three times per day for three months. After this duration, we reevaluated them by ultrasound at days 14, 21. Results: Metformin therapy resulted in a significant increase of endometrial thickness and had a significant decrease on uterine, endometrial and subendometrial resistance index (R.I) and pulsatility index (P.I) at day 14, 21 compared to pre-treatment values indicating better blood flow. Conclusion: Metformin therapy resulted in improvement of endometrial flow patterns. Also, it resulted in increase in endometrial thickness and improvement of uterine artery flow.
\end{abstract}




\section{Keywords}

Endometrial Thickness, Subendometrial Flow Patterns, Anovulatory PCOS, Metformin

\section{Introduction}

Most women with polycystic ovarian syndrome (PCOS) have some degree of insulin resistance. It is a known fact that hyperinsulinemia augments androgen production in PCOS [1]. Insulin resistance has further been associated with abnormal endometrial development and endometrial defects in women with PCOS. [2]. Abnormal uterine blood flow has been observed in women with PCOS; the subfertile population in general [3] and in women with idiopathic recurrent miscarriage [4].

Infertility associated with PCOS also results from chronic anovulation. There are increasing data suggesting that implantation failure can further reduce pregnancy rates in these women [5]. Although ovulation is readily obtained with medical induction, implantation rates remain lower than fertile controls and early pregnancy loss rates are increased [2].

Metformin, an insulin sensitizer, is widely used in women with PCOS to correct this biochemical disorder helping ovulation [6]. One study reported that insulin reduction with metformin enhanced uterine vascularity and reduced uterine vascular resistance, as demonstrated by a $20 \%$ reduction in vascular resistance in spiral arteries after metformin use [2]. Endometrial receptivity could be indirectly assessed by ultrasound. This includes the assessment of uterine artery velocimetry and the endometrial characteristics such as thickness, pattern and vascularity [7].

In the current study, we evaluated the effect of metformin received by anovulatory patients with PCOS on endometrial thickness and endometrial vascular flow patterns, in addition to ovulation and pregnancy rates in these women.

\section{Patients and Methods}

Eighty five patients complaining of infertility due to chronic anovulation associated with PCOS were recruited from Ain Shams University Outpatient Infertility Clinic from January $1^{\text {st }}, 2018$ until June $30^{\text {th }}, 2018$. Patients were between 20 and 35 years of age complaining of irregular menses and fulfilling the following criteria for diagnosis of PCOS according to the Androgen Excess and Polycystic Ovarian Syndrome Society [8]:

- presence of hyperandrogenism in the form of hirsutism and/or hyperandrogenaemia;

- presence of ovarian dysfunction in the form of oligo or anovulation and/or polycystic ovaries by transvaginal ultrasound.

- exclusion of other causes of androgen excess or related disorders like defi- 
cient non-classic adrenal hyperplasia, androgen-secreting neoplasms, androgenic/anabolic drug use or abuse, Cushing's syndrome, the Hyperandrogenic-Insulin Resistance-Acanthosis Nigricans Syndrome, thyroid dysfunction and hyperprolactinemia.

Patients with regular monthly menses, receiving weight loss eating programs and/or physical exercising were excluded. Furthermore, patients with chronic medical disorders or with uterine fibroids or endometriosis or patients with endocrinological disorders like diabetes mellitus, hypothyroidism, hyperprolactinaemia, Cushing's syndrome and non-classical congenital adrenal hyperplasia were also excluded.

The current study was approved by the Ethical Committee of the Department of Obstetrics and Gynecology, Faculty of Medicine, Ain Shams University. It was registered on Clinical trial.gov with I.D:NCT03486626. Written informed consents were obtained from all participants.

Pretreatment with metformin, all participants were subjected to detailed history taking and examination, including body mass index (BMI) calculation and hirsutism scoring using modified Ferriman Gallwey Index [9]. Hormonal profiles for all patients were determined including follicle stimulating hormone (FSH), luteinizing hormone (LH), prolactin, thyroid stimulating hormone (TSH), androstienodione, free testosterone and 17-hydroxyprogesterone. Serum progesterone level was also measured on day 21 after withdrawal bleeding due to progestin administration. A value less than $3 \mathrm{ng} / \mathrm{ml}$ confirmed anovulation in these patients (Figure 1). Transvaginal ultrasound was done for all participants on days 14 and 21 to determine endometrial thickness, uterine artery flow pattern,

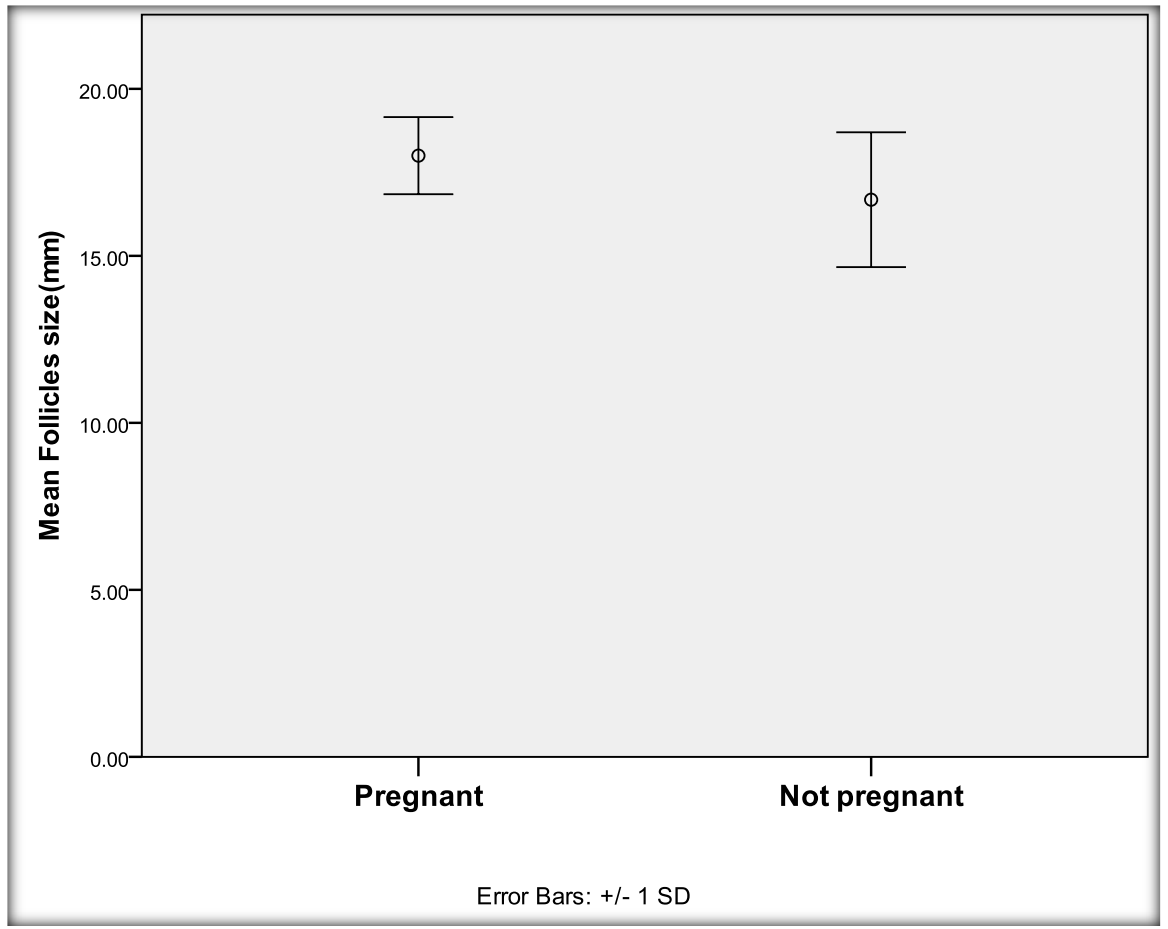

Figure 1. Comparison between pregnant and not pregnant regarding follicle size. 
endometrial and subendometrial flow patterns. Samsung R5 ultrasound machine equipped with a $7.5 \mathrm{MHz}$ vaginal probe was used. Uterus was visualized in the longitudinal section. Endometrial thickness was identified as a double layer and maximum distance between each myometrial/endometrial interface was measured. Colour flow images of the ascending main branch of the right and left uterine arteries at the level of the internal os in a longitudinal plane before it entered the uterus were visualized and studied by positioning a sample volume over the area of maximum color and by activating the pulsed Doppler. The mean of three consecutive waveforms of good quality were analyzed. Blood flow impedances of both uterine arteries were calculated and expressed as pulsatility index $[\mathrm{PI}=$ (peak systolic velocity - peak diastolic velocity)/mean velocity] and resistance index $[\mathrm{RI}=$ (peak systolic velocity - peak diastolic velocity)/peak systolic velocity]. Furthermore, color flow images of endometrial blood vasculature and subendometrial vessels lying within $10 \mathrm{~mm}$ of the echogenic endometrial borders were detected by color Doppler energy and PI and RI were calculated electronically when three similar, consecutive waveforms of good quality were obtained.

All participants received metformin $500 \mathrm{mg}$ three times daily for three months. After this duration, transvaginal ultrasound was done on days 14 and 21 of a spontaneous or progestin induced menses. Serum progesterone on day 21 of a spontaneous or progestin induced menses was measured and ovulation was confirmed by a level $>3 \mathrm{ng} / \mathrm{ml}$ on day 21 of the cycle.

N.B: We measured serum progesterone on day 21 of progestin induced menses in patients with amenorrhea and in patients who got regular menses every 28 days with metformin treatment. Serum progesterone was measured one week before time of expected menses in patients who got regular cycles longer than 28 days, for example day 28 of 35 day cycle.

During the 3 months period of metformin treatment, we asked the participants to measure serum B-hCG monthly in patients with amenorrhea or one week after missed period in patients who regular menses with metformin treatment.

Data analysis was done using SPSS program version 24. Quantitative variables were presented as mean and standard deviation, while qualitative variables were presented as count and percent. Student $t$ test was used to compare quantitative variables between two independent groups and paired samples $t$ test was used to compare them before and after treatment for the same group. A p-value $<0.05$ was considered statistically significant.

\section{Results}

In our study, 85 patients with anovulatory PCOS were investigated. Their demographic data and hormonal profile are shown in Table 1. Table 2 shows that there is a statistically significant difference between all ultrasonographic results before and after treatment. Pretreatment endometrial thickness on day 14 was 
Table 1. Personal data and baseline hormonal profile.

\begin{tabular}{|c|c|c|c|c|c|}
\hline & $\mathbf{N}$ & Minimum & Maximum & Mean & SD \\
\hline Age(years) & 85 & 20.00 & 36.00 & 24.95 & 3.36 \\
\hline $\operatorname{BMI}\left(\mathrm{kg} / \mathrm{m}^{2}\right)$ & 85 & 21.40 & 43.00 & 30.23 & 4.33 \\
\hline Waist/hip ratio & 85 & 0.82 & 0.90 & 0.86 & 0.02 \\
\hline Modified FerrimanGallway score & 85 & 12.00 & 19.00 & 16.15 & 1.59 \\
\hline $\mathrm{FSH}(\mathrm{mIU} / \mathrm{ml})$ & 85 & 3.60 & 12.00 & 5.80 & 1.33 \\
\hline $\mathrm{LH}(\mathrm{mIU} / \mathrm{ml})$ & 85 & 2.40 & 16.80 & 10.06 & 2.85 \\
\hline $\mathrm{E} 2(\mathrm{pg} / \mathrm{ml})$ & 85 & 23.00 & 78.00 & 42.80 & 12.66 \\
\hline Prolactin (ng/ml) & 85 & 3.60 & 25.00 & 12.36 & 4.97 \\
\hline $\mathrm{TSH}(\mu \mathrm{IU} / \mathrm{ml})$ & 85 & 0.49 & 3.00 & 1.39 & 0.60 \\
\hline Progesterone (nmol/l) & 85 & 1.25 & 3.26 & 2.48 & 0.50 \\
\hline 17-OH-Progesterone (nmol/l) & 85 & 3.10 & 79.00 & 6.12 & 8.10 \\
\hline Androstenedione (nmol/l) & 85 & 5.00 & 6.00 & 5.54 & 0.29 \\
\hline Free Testosterone (pg/dl) & 85 & 0.30 & 16.00 & 2.07 & 1.75 \\
\hline
\end{tabular}

Table 2. Comparison between ultrasonographic findings before and after treatment.

\begin{tabular}{|c|c|c|c|c|c|c|c|c|c|}
\hline & \multicolumn{2}{|c|}{ Pre } & \multicolumn{2}{|c|}{ Post } & \multirow{2}{*}{$\mathrm{t}^{*}$} & \multirow{2}{*}{ Mean diff. } & \multicolumn{2}{|c|}{$95 \% \mathrm{CI}$ for diff. } & \multirow{2}{*}{$P$ value } \\
\hline & Mean & SD & Mean & SD & & & Lower & Upper & \\
\hline Endometrial Thickness day $14(\mathrm{~mm})$ & 6.67 & 1.14 & 11.82 & 2.25 & 17.355 & -5.15217 & -5.74457 & -4.55978 & $<0.001$ \\
\hline Endometrial thickness day $21(\mathrm{~mm})$ & 7.84 & 1.13 & 13.21 & 1.50 & 23.943 & -5.36957 & -5.81708 & -4.92205 & $<0.001$ \\
\hline Endometrial vascularity P.I day 14 & 0.93 & 0.09 & 0.80 & 0.09 & 8.584 & 0.13159 & 0.10100 & 0.16219 & $<0.001$ \\
\hline Endometrial vascularity R.I day 14 & 0.63 & 0.06 & 0.54 & 0.10 & 7.254 & 0.09493 & 0.06881 & 0.12104 & $<0.001$ \\
\hline Subendometrial vascularity P.I day 14 & 0.90 & 0.07 & 0.79 & 0.09 & 9.010 & 0.10826 & 0.08428 & 0.13224 & $<0.001$ \\
\hline Subendometrial vascularity R.I day 14 & 0.91 & 0.06 & 0.57 & 0.06 & 33.000 & -0.33754 & -0.35795 & -0.31713 & $<0.001$ \\
\hline Endometrial vascularity P.I day 21 & 0.96 & 0.11 & 0.77 & 0.08 & 10.972 & 0.18812 & 0.15390 & 0.22233 & $<0.001$ \\
\hline Endometrial vascularity R.I day 21 & 0.64 & 0.07 & 0.52 & 0.07 & 9.611 & 0.11638 & 0.09221 & 0.14054 & $<0.001$ \\
\hline Subendometrial vascularity P.I day 21 & 0.95 & 0.05 & 0.77 & 0.06 & 18.817 & 0.18116 & 0.16195 & 0.20037 & $<0.001$ \\
\hline Subendometrial vascularity R.I day 21 & 0.65 & 0.06 & 0.54 & 0.07 & 1.580 & 0.10899 & -0.02862 & 0.24660 & 0.119 \\
\hline Uterine artery doppler P.I day 14 & 3.50 & 0.55 & 2.75 & 0.26 & 10.634 & 0.74667 & 0.60656 & 0.88678 & $<0.001$ \\
\hline Uterine artery doppler R.I day 14 & 0.94 & 0.10 & 0.86 & 0.08 & 6.090 & 0.08203 & 0.05515 & 0.10891 & $<0.001$ \\
\hline Uterine artery doppler P.I day 21 & 3.42 & 0.61 & 2.70 & 0.25 & 8.309 & 0.72348 & 0.54973 & 0.89723 & $<0.001$ \\
\hline Uterine artery Doppler R.I day 21 & 0.95 & 0.08 & 0.82 & 0.08 & 9.038 & 0.12275 & 0.09565 & 0.14986 & $<0.001$ \\
\hline
\end{tabular}

${ }^{*}$ Paired samples $\mathrm{t}$ test.

$6.67 \pm 1.14 \mathrm{~mm}$ and on day 21 was $7.84 \pm 1.13 \mathrm{~mm}$ while post-treatment value was $11.82 \pm 2.25 \mathrm{~mm}$ and $13.21 \pm 1.50 \mathrm{~mm}$ respectively $(\mathrm{p}<0.001)$. Pretreatment values of uterine artery P.I and R.I on day 14 were $3.50 \pm 0.55,0.94 \pm 0.1$ and on day 21 were $3.42 \pm 0.61,0.95 \pm 0.08$ respectively, while post-treatment 
values on day 14 were $2.75 \pm 0.26,0.86 \pm 0.08$ and on day 21 were $3.42 \pm 0.61$, $0.95 \pm 0.08$ respectively, $(\mathrm{p}<0.001)$. Pretreatment values of endometrial vessels P.I and R.I on day 14 were $0.93 \pm 0.09,0.63 \pm 0.06$ and on day 21 were $0.96 \pm$ $0.11,0.64 \pm 0.07$ respectively, while post-treatment values on day 14 were $0.80 \pm$ $0.09,0.54 \pm 0.1$ and on day 21 were $0.77 \pm 0.08,0.52 \pm 0.07$ respectively; $(\mathrm{p}<$ $0.001)$. Pretreatment values of subendometrial vessels P.I and R.I on day 14 were $0.90 \pm 0.07,0.91 \pm 0.06$ and on day 21 were $0.95 \pm 0.05,0.65 \pm 0.06$ respectively, while post-treatment values on day 14 were $0.79 \pm 0.09,0.57 \pm 0.06$ and on day 21 were $0.77 \pm 0.06,0.54 \pm 0.07$ respectively (Figure 2 ).

Spontaneous ovulation occurred in $30.6 \%$ of patients. Spontaneous pregnancy occurred in 16 patients $(18.8 \%)$. Twelve patients got pregnant in the $3^{\text {rd }}$ month of treatment, while 3 patients got pregnant in the $2^{\text {nd }}$ month of treatment and only one patient got pregnant in the $1^{\text {st }}$ month of treatment. Table 3 shows that there is a statistically insignificant difference between all personal data and hormonal profiles between pregnant and non-pregnant patients. Table 4 shows that there is no statistically significant difference regarding ultrasound data between pregnant and non-pregnant participants before treatment with metformin ( $\mathrm{p}>$ 0.05 ) except for 2 measurements which are endometrial flow R.I on day 21 and subendometrial flow P.I on day 21 which were significantly different $(\mathrm{p}<0.001)$ (Figure 3).

\section{Discussion}

For Implantation to be of great success, it depends on an interaction between the

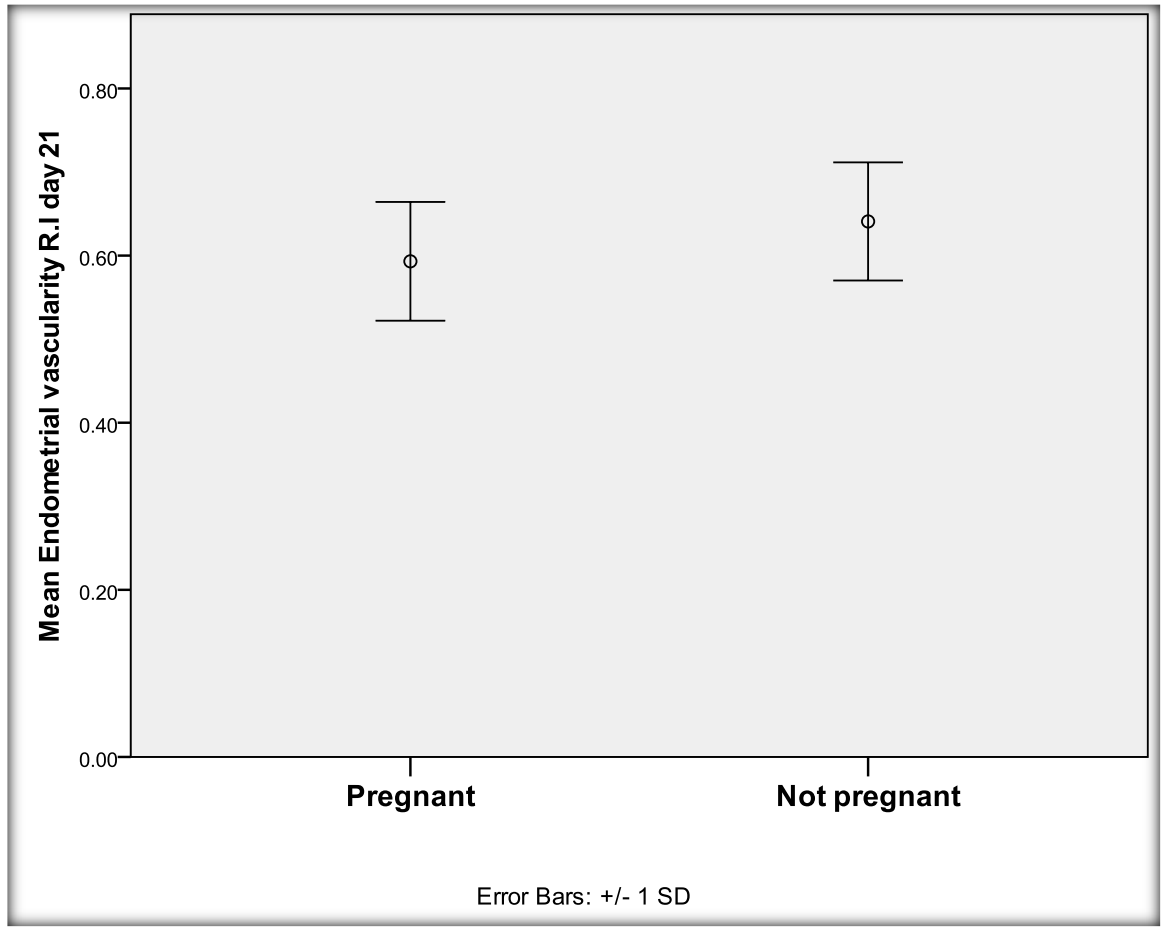

Figure 2. Comparison between pregnant and not pregnant regarding endometrial vascularity R.I day 21 before treatment. 
Table 3. Comparison between pregnant and non-pregnant regarding personal data and baseline hormonal profile.

\begin{tabular}{|c|c|c|c|c|c|c|c|c|c|}
\hline & \multicolumn{2}{|c|}{$\begin{array}{l}\text { Pregnant } \\
(\mathrm{N}=16)\end{array}$} & \multicolumn{2}{|c|}{$\begin{array}{l}\text { Not pregnant } \\
\quad(N=69)\end{array}$} & \multirow[t]{2}{*}{$t^{*}$} & \multirow[t]{2}{*}{ Mean diff. } & \multicolumn{2}{|c|}{$95 \%$ CI for diff. } & \multirow[t]{2}{*}{$P$ value } \\
\hline & Mean & SD & Mean & SD & & & Lower & Upper & \\
\hline Age (years) & 24.63 & 2.66 & 25.03 & 3.51 & 0.432 & -0.40399 & -2.26490 & 1.45693 & 0.667 \\
\hline BMI $\left(\mathrm{kg} / \mathrm{m}^{2}\right)$ & 31.34 & 3.65 & 29.97 & 4.46 & 1.147 & 1.37708 & -1.01056 & 3.76473 & 0.255 \\
\hline waist/hip ratio & 0.86 & 0.02 & 0.86 & 0.02 & 0.453 & -0.00222 & -0.01195 & 0.00751 & 0.651 \\
\hline Modified FerrimanGallway score & 16.19 & 1.87 & 16.14 & 1.54 & 0.096 & 0.04257 & -0.84150 & 0.92665 & 0.924 \\
\hline $\mathrm{FSH}(\mathrm{mIU} / \mathrm{ml})$ & 5.42 & 0.85 & 5.89 & 1.41 & 1.292 & -0.47487 & -1.20590 & 0.25615 & 0.200 \\
\hline $\mathrm{LH}(\mathrm{mIU} / \mathrm{ml})$ & 9.70 & 1.78 & 10.15 & 3.04 & 0.779 & -0.44931 & -1.61624 & 0.71762 & 0.441 \\
\hline $\mathrm{E} 2(\mathrm{pg} / \mathrm{ml})$ & 42.96 & 11.50 & 42.77 & 13.00 & 0.054 & 0.19103 & -6.83959 & 7.22165 & 0.957 \\
\hline Prolactin (ng/ml) & 13.66 & 5.73 & 12.06 & 4.78 & 1.163 & 1.60076 & -1.13786 & 4.33938 & 0.248 \\
\hline $\mathrm{TSH}(\mu \mathrm{IU} / \mathrm{ml})$ & 1.16 & 0.48 & 1.44 & 0.62 & 1.726 & -0.28535 & -0.61416 & 0.04346 & 0.088 \\
\hline Progesterone (nmol/l) & 2.37 & 0.49 & 2.50 & 0.51 & 0.937 & -0.13106 & -0.40917 & 0.14705 & 0.351 \\
\hline 17-OH-Progesterone (nmol/1) & 4.83 & 1.08 & 6.41 & 8.96 & 0.703 & -1.58324 & -6.06494 & 2.89846 & 0.484 \\
\hline Androstenedione (nmol/l) & 5.56 & 0.30 & 5.54 & 0.29 & 0.209 & 0.01712 & -0.14592 & 0.18016 & 0.835 \\
\hline Free Testosterone (pg/dl) & 1.91 & 0.79 & 2.11 & 1.91 & 0.424 & -0.20679 & -1.17650 & 0.76292 & 0.673 \\
\hline
\end{tabular}

*Student $\mathrm{t}$ test.

Table 4. Comparison between pregnant and non-pregnant regarding ultrasonographic data before treatment.

\begin{tabular}{|c|c|c|c|c|c|c|c|c|c|}
\hline & \multicolumn{2}{|c|}{$\begin{array}{l}\text { Pregnant } \\
(\mathrm{N}=16)\end{array}$} & \multicolumn{2}{|c|}{$\begin{array}{l}\text { Not pregnant } \\
\quad(\mathrm{N}=69)\end{array}$} & \multirow{2}{*}{$t^{*}$} & \multirow{2}{*}{ Mean diff. } & \multicolumn{2}{|c|}{$95 \% \mathrm{CI}$ for diff. } & \multirow{2}{*}{$P$ value } \\
\hline & Mean & SD & Mean & SD & & & Lower & Upper & \\
\hline Endometrial Thickness day $14(\mathrm{~mm})$ & 6.96 & 1.46 & 6.67 & 1.14 & 0.869 & 0.28958 & -0.37349 & 0.95266 & 0.388 \\
\hline Endometrial thickness day $21(\mathrm{~mm})$ & 8.14 & 1.65 & 7.84 & 1.13 & 0.875 & 0.30172 & -0.38419 & 0.98763 & 0.384 \\
\hline Endometrial vascularity P.I day 14 & 0.93 & 0.09 & 0.93 & 0.09 & 0.061 & 0.00149 & -0.04711 & 0.05010 & 0.951 \\
\hline Endometrial vascularity R.I day 14 & 0.63 & 0.07 & 0.63 & 0.06 & 0.071 & -0.00130 & -0.03774 & 0.03513 & 0.943 \\
\hline Subendometrial vascularity P.I day 14 & 0.91 & 0.06 & 0.90 & 0.07 & 0.417 & 0.00749 & -0.02823 & 0.04321 & 0.678 \\
\hline Subendometrial vascularity R.I day 14 & 0.56 & 0.08 & 0.57 & 0.06 & 0.758 & -0.01390 & -0.05041 & 0.02260 & 0.451 \\
\hline Endometrial vascularity P.I day 21 & 0.95 & 0.11 & 0.96 & 0.11 & 0.174 & -0.00524 & -0.06513 & 0.05466 & 0.862 \\
\hline Endometrial vascularity R.I day 21 & 0.59 & 0.07 & 0.64 & 0.07 & 2.432 & -0.04774 & -0.08679 & -0.00870 & 0.017 \\
\hline Subendometrial vascularity P.I day 21 & 0.91 & 0.04 & 0.95 & 0.05 & 2.883 & -0.03884 & -0.06564 & -0.01204 & 0.005 \\
\hline Subendometrial vascularity R.I day 21 & 0.55 & 0.05 & 0.65 & 0.56 & 0.676 & -0.09480 & -0.37372 & 0.18412 & 0.501 \\
\hline Uterine artery doppler P.I day 14 & 3.73 & 0.54 & 3.50 & 0.55 & 1.507 & 0.22928 & -0.07338 & 0.53193 & 0.136 \\
\hline Uterine artery doppler R.I day 14 & 0.93 & 0.07 & 0.94 & 0.10 & 0.190 & -0.00485 & -0.05547 & 0.04577 & 0.849 \\
\hline Uterine artery doppler P.I day 21 & 3.32 & 0.48 & 3.42 & 0.61 & 0.626 & -0.10197 & -0.42585 & 0.22191 & 0.533 \\
\hline Uterine artery Doppler R.I day 21 & 0.92 & 0.08 & 0.95 & 0.08 & 1.338 & -0.02955 & -0.07346 & 0.01436 & 0.184 \\
\hline
\end{tabular}

${ }^{*}$ Student $\mathrm{t}$ test. 


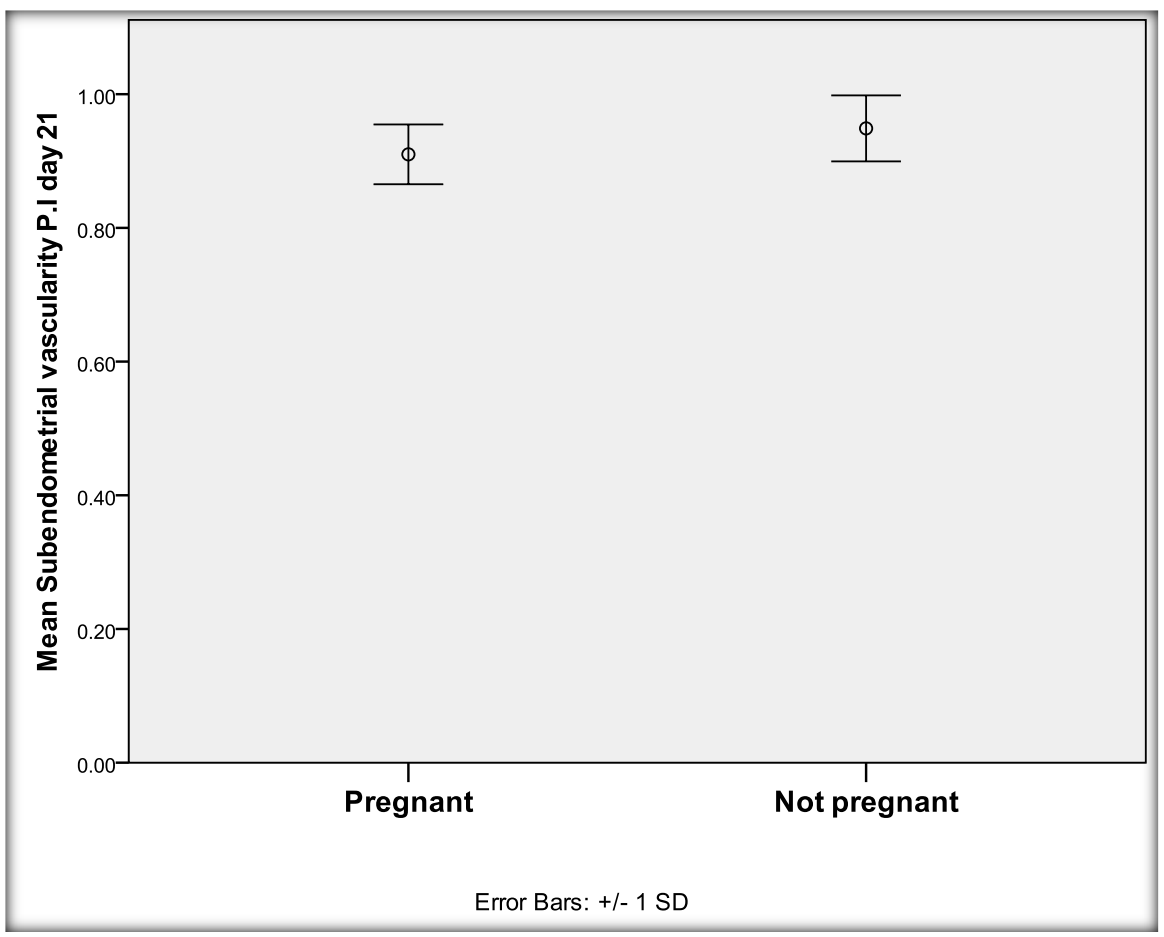

Figure 3. Comparison between pregnant and not pregnant regarding subendometrial vascularity P.I day 21 before treatment.

receptive endometrium and the blastocyst. Endometrial receptivity can be evaluated by histologic evaluation of an endometrial biopsy, endometrial proteins in uterine flushing, or more commonly ultrasound examination of the endometrium. Different ultrasound parameters have been used to assess endometrial receptivity including endometrial thickness, endometrial pattern, endometrial volume, Doppler study of uterine arteries, and endometrial blood flow. [10]

Anovulatory women with PCOS were investigated before and after 3 months of treatment with metformin regarding endometrial thickness, uterine, endometrial and subendometrial vascular indices. Endometrium was significantly thinner before the treatment. All vascular indices were significantly higher before treatment with metformin compared to post-treatment values. These results were the same as Palomba et al. [11]

Battaglia et al. concluded that anovulatory patients with PCOS have an alteration in uterine vascularization [12]. In fact, PI and RI values, two measures of blood impedance inversely related to blood flow, were not only unchanged throughout the cycle [13] but also significantly higher before the treatment.

In the current study, it was found that uterine Doppler indices were increased in PCOS patients and this is similar to the study done by Mohsen et al. [14]. The uterine artery Doppler indices were reduced upon treatment by metformin as all the patients had hyperandrogensim. It suggested that uterine blood flow was reduced in women with PCOS who had hyperandrogenism or were obese [15]. This indicates that the PCO syndrome with hyperandrogensim can decrease the uterine, endometrial and subendometrial flow patterns which are indirect indi- 
cators of endometrial receptivity [16].

In the current study, metformin therapy led to significant increase in endometrial thickness and had a significant effect on uterine RI and PI. On the endometrial level, endometrial and subendometrial R.I and P.I were significantly reduced after metformin treatment indicating better blood flow. In response to metformin therapy, ovulation was achieved in 26 women (30.6\%). Pregnancy rate was $18.8 \%$. Twelve patients got pregnant in the $3^{\text {rd }}$ month of treatment. That may be explained by the cumulative effect of metformin action. There were no significant differences between pregnant and non-pregnant women regarding endometrial thickness, personal data nor hormonal profiles. Likewise, pretreatment values of uterine RI and PI were insignificantly different in pregnant compared to non-pregnant women; however, decreased endometrial flow R.I on day 21 and decreased subendometrial flow P.I on day 21 was significantly different.

Metformin did improve the ovulation and clinical pregnancy rates when added to letrozole or clomiphene citrate for ovulation induction in PCOS patients this is attributed to the addition of either letrozole or clomiphene citrate [17]. Endometrial thickness was considered a marker for uterine receptivity and for pregnancy prediction with different results. Although Kocak et al. [18] demonstrated a significant effect of metformin on endometrial thickness in PCOS women treated with clomiphene citrate, the study done by Maged et al. [19] showed that there was no improvement in endometrial thickness with metformin therapy and that treatment with $\mathrm{N}$-Acetyl Cysteine was superior to metformin. In the current study, metformin treatment increased endometrial thickness significantly. This variation in results could be attributed to the lower Ferriman Gallway starting score used or the different inclusion criteria. The results of the current study demonstrated the vascular effect of metformin on the endometrium and uterine artery flow pattern. It also demonstrated an improvement of endometrial and subendometrial flow patterns after metformin therapy.

\section{Limitation of the Study}

Longer duration of treatment might give more conclusive results. Also investigating hormonal profile post treatment could have been done to give an idea on whether metformin has an effect on the hormonal profile in this group of patients. Better assessment of the parameters of the endometrium should have been done by 3-dimensional ultrasound.

\section{Conclusion}

We can conclude that endometrial vascularity was abnormally reduced in women with anovulatory PCOS. Metformin therapy improves endometrial flow pattern. In addition, it increases endometrial thickness and improved impedance observed in uterine artery flow observed in women with PCOS. We acknowledge that this study suggests that changes in the endometrial and subendometrial blood flow in some women with PCOS are only a preliminary one. The overlap 
of the variables also renders it impossible to establish a practical cut-off level.

\section{Acknowledgements}

Special thanks goes to the U/S team of Ain Shams University Maternity Hospital who participated in the study and to our patients for great support to our work. Also, special thanks to Prof. Dr/Alaa Sayed Abdelhafeez for her great support and help.

\section{Funding}

No funds were received from any funding agency.

\section{Conflicts of Interest}

No potential conflict of interest was reported by the authors.

\section{Informed Consent}

Informed consents were obtained from all participants.

\section{References}

[1] Blank, S.K., McCartney, C.R., Chhabra, S., Helm, K.D., Eagleson, C.A., Chang, R.J., et al. (2009) Modulation of GnRH Pulse Generator Sensitivity to Progesterone Inhibition in Hyperandrogenemic Adolescent Girls: Implications for Regulation of Pubertal Maturation. The Journal of Clinical Endocrinology \& Metabolism, 94, 2360-2366.

[2] Jakubowicz, D.J., Seppala, M., Jakubowicz, S., Rodriguez-Armas, O., Rivas-Santiago, A., Koistinen, H., Koistinen, R. and Nestler, J.E. (2001) Insulin Reduction with Metformin Increases Luteal Phase Serum Glycodelin and Insulin-Like Growth Factor-Binding Protein 1 Concentrations and Enhances Uterine Vascularity and Blood Flow in the Polycystic Ovary Syndrome. The Journal of Clinical Endocrinology \& Metabolism, 86, 1126-1133.

[3] Isaksson, R., Tiitinen, A., Reinikainen, L.M. and Cacciatore, B. (2003) Comparison of Uterine and Spiral Artery Blood Flow in Women with Unexplained and Tubal Infertility. Ultrasound in Obstetrics \& Gynecology, 21, 174-180. https://doi.org/10.1002/uog.27

[4] Ferreira, A.M., Pires, C.R., Moron, A.F., Araujo, E., Traina, E. and Mattar, R. (2007) Doppler Assessment of Uterine Blood Flow in Recurrent Pregnancy Loss. International Journal of Gynecology \& Obstetrics, 98, 115-119. https://doi.org/10.1016/j.ijgo.2007.05.006

[5] Korgun, E.T., Denir, R., Hammer, A., Dohr, G., Desoye, G., Skofitch, G. and Hahn, T. (2001) Glucose Transporter Expression in Rat Embryo and Uterus during Decidualization, Implantation, and Early Postimplantation. Biology of Reproduction, 65, 1364-1370. https://doi.org/10.1095/biolreprod65.5.1364

[6] Creanga, A.A., Bradley, H.M., McCormick, C. and Witkop, C.T. (2008) Use of Metformin in Polycystic Ovary Syndrome: A Meta-Analysis. Obstetrics \& Gynecology, 111, 959-968. https://doi.org/10.1097/AOG.0b013e31816a4ed4

[7] Pierson, R.A. (2003) Imaging the Endometrium: Are There Predictors of Uterine Receptivity? Journal of Obstetrics and Gynaecology Canada, 25, 360-368. 
https://doi.org/10.1016/S1701-2163(16)30578-3

[8] Azziz, R., Carmina, E., Dewailly, D., Diamanti-Kandarakis, E., EscobarMorreale, H.F., Futterweit, W., et al. (2009) The Androgen Excess and PCOS Society Criteria for the Polycystic Ovary Syndrome: The Complete Task Force Report. Fertility and Sterility, 91, 456-488. https://doi.org/10.1016/j.fertnstert.2008.06.035

[9] Archer, J.S. and Chang, R.J. (2004) Hirsutism and Acne in Polycystic Ovary Syndrome. Best Practice \& Research Clinical Obstetrics \& Gynaecology, 18, 737-54

[10] Tropea, A., Miceli, F., Minici, F., Orlando, M., Lamanna, G., Gangale, M., Catino, S., Lanzone, A. and Apa, R. (2004) Endometrial Evaluation in Superovulation Programs: Relationship with Successful Outcome. Annals of the New York Academy of Sciences, 1034, 211-218. https://doi.org/10.1196/annals.1335.023

[11] Palomba, S., Russo, T., Orio, F., Falbo, A., Manguso, F., Cascella, T., Tolino, A., Carmina, E., Colao, A. and Zullo, F. (2006) Uterine Effects of Metformin Administration in Anovulatory Women with Polycystic Ovary Syndrome. Human Reproduction, 21, 457-465. https://doi.org/10.1093/humrep/dei351

[12] Battaglia, C., Mancini, F., Persico, N., Zaccaria, V. and de Aloysio, D. (2004) Ultrasound Evaluation of PCO, PCOS and OHSS. Reproductive Biomedicine Online, 9, 614-619. https://doi.org/10.1016/S1472-6483(10)61770-1

[13] Vrtačnik-Bokal, E., Meden-Vrtovec, H. and Verdenik, I. (2006) Uterine Arterial Blood Flow and the Substances of Ovarian Renin-Angiotensin System in Women with Polycystic Ovaries Undergoing In Vitro Fertilization. European Journal of $O b$ stetrics \& Gynecology and Reproductive Biology, 124, 77-81.

https://doi.org/10.1016/j.ejogrb.2005.08.004

[14] Mohsen, I.A., Elkattan, E., Nabil, H. and Khattab, S. (2013) Effect of Metformin Treatment on Endometrial Vascular Indices in Anovulatory Obese/Overweight Women with Polycystic Ovarian Syndrome Using Three-Dimensional Power Doppler Ultrasonography. Journal of Clinical Ultrasound, 41, 275-282. https://doi.org/10.1002/jcu.22006

[15] Özkan, S., Vural, B., Çalışkan, E., Bodur, H., Türköz, E. and Vural, F. (2007) Color Doppler Sonographic Analysis of Uterine and Ovarian Artery Blood Flow in Women with Polycystic Ovary Syndrome. Journal of Clinical Ultrasound, 35, 305-313. https://doi.org/10.1002/jcu.20358

[16] Rosenfield, R.L. and Ehrmann, D.A. (2016) The Pathogenesis of Polycystic Ovary Syndrome (PCOS): The Hypothesis of PCOS as Functional Ovarian Hyperandrogenism Revisited. Endocrine Reviews, 37, 467-520. https://doi.org/10.1210/er.2015-1104

[17] Khan, Z., Khan, R., Bukhari, A.S. and Ahmad, W. (2017) Comparative Effectiveness of Ovulation Induction Therapy in Women with Polycystic Ovarian Syndrome. Journal of the Society of Obstetrics and Gynaecologists of Pakistan, 7, 128-132.

[18] Kocak, M., Caliskan, E., Simsir, C. and Haberal, A. (2002) Metformin Therapy Improves Ovulatory Rates, Cervical Scores, and Pregnancy Rates in Clomiphene Citrate-Resistant Women with Polycystic Ovary Syndrome. Fertility and Sterility, 77, 101-106. https://doi.org/10.1016/S0015-0282(01)02941-7

[19] Maged, A.M., Elsawah, H., Abdelhafez, A., Bakry, A. and Mostafa, W.A. (2015) The Adjuvant Effect of Metformin and N-Acetylcysteine to Clomiphene Citrate in Induction of Ovulation in Patients with Polycystic Ovary Syndrome. Gynecological Endocrinology, 31, 635-638. https://doi.org/10.3109/09513590.2015.1037269 